\title{
Yoga nas escolas: percepção de crianças e seus responsáveis sobre seus efeitos
}

\author{
Yoga in schools: perception of children and their \\ guardians about its effects
}

\section{Yoga en las escuelas: percepción de los niños y sus responsables de sus efectos}

\author{
iD) Érica Maria Corrêa \\ Universidade de São Paulo, São Paulo, São Paulo, Brasil. \\ ericayoga@alumni.usp.br \\ (iD) Paula Hentschel Lobo da Costa \\ Universidade Federal de São Carlos, São Carlos, São Paulo, Brasil. \\ paulahlc@ufscar.br
}

Resumo: O objetivo deste estudo foi avaliar a percepção de crianças e de seus responsáveis quanto aos efeitos de uma prática regular de Yoga realizada na escola. Os resultados foram analisados através da metodologia do Discurso do Sujeito Coletivo (DSC) que construiu, a partir dos depoimentos coletados, grupos de discursos que representaram as experiências vivenciadas pelo coletivo. Segundo os relatos das crianças e dos seus responsáveis, foram percebidas melhoras na calma, na concentração e aumento na qualidade das interações sociais das crianças após as 12 semanas de prática regular de Yoga na escola, porém, consideraram a intervenção de curta duração.

Palavras-chave: Yoga. Escolares. Discurso do Sujeito Coletivo.

Abstract: The aim of this study was to assess the perception of children and their guardians regarding the effects of a regular Yoga practice performed at school. The results were analyzed using the 
Collective Subject Discourse (DSC) methodology that built, from the collected statements, groups of discourses that represented the experiences lived by the collective. According to the reports of the children and their guardians, improvements in calmness, concentration and an increase in the quality of social interactions in the children were noticed after the 12 weeks of regular Yoga practice at school, but considered the intervention to be of short duration.

Keywords: Yoga. School. Collective Subject Discourse.

Resumen: El objetivo de este estudio fue evaluar la percepción de los niños y sus tutores sobre los efectos de una práctica regular de Yoga realizada en la escuela. Los resultados fueron analizados utilizando la metodología del Discurso Colectivo del Sujeto (DSC) que construyó, a partir de los enunciados recopilados, grupos de discursos que representaron las experiencias vividas por el colectivo. Según los informes de los niños y sus tutores, se notaron mejoras en la calma, concentración y un aumento en la calidad de las interacciones sociales en los niños después de las 12 semanas de práctica regular de Yoga en la escuela, pero consideraron la intervención ser de corta duración.

Palabras clave: Yoga. Colegio. Discurso Colectivo Del Sujeto.

Submetido em: 13-02-2021

Aceito em: 18-05-2021 
Yoga nas escolas: percepção de crianças e seus responsáveis sobre seus efeitos

\section{Introdução}

O desempenho escolar depende de múltiplos fatores que vão além da capacidade cognitiva, tais como: atenção, memória, interesse, controle da impulsividade, interação com professores/as e outras crianças, por exemplo. Sabe-se que há correlações entre indicadores de desatenção e hiperatividade com baixos desempenhos em funções executivas e de aprendizagem escolar (PEREIRA et al., 2012). Por esta razão, educadores/as e profissionais clínicos oferecem alternativas dentro do currículo escolar na forma de atividades complementares, a fim de estimular a formação integral da criança e uma vida escolar mais saudável e plena (SANTOS et al., 2013).

Nesse contexto, a prática do Yoga tem sido uma aliada valiosa para promover a saúde física e mental de crianças e jovens. O Yoga é utilizado na Medicina como forma de tratamento complementar em casos de distúrbio de atenção e hiperatividade (BIRDEE et al., 2009), distúrbios alimentares (BENAVIDES et al., 2009), estresse (EHUD et al., 2003; HAGINS et al., 2013), para a melhor regulação da frequência cardíaca, redução da ansiedade e da depressão (GALANTINO et al., 2008), problemas de saúde física (HAGEN et al., 2014; KHALSA et al., 2012), para o bem-estar psicossocial (NOGGLE et al., 2012) e para melhoria na memória (SAROKTE et al., 2013) em crianças e adolescentes. O próprio Ministério da Saúde criou, em 2006, a Política Nacional de Práticas Integrativas e Complementares (PNPIC) que atende usuários do Sistema Único de Saúde dentro de Unidades Básicas de Saúde, além de níveis secundário e terciário de atendimento (portaria do Ministério da Saúde de número 971, de 3 de maio de 2006), tendo sido o Yoga incluído como um dos procedimentos reconhecidos em 2017 (portaria do Ministério da Saúde de número 849, de 27 de março de 2017).

Segundo Gharote (2005), o Yoga é uma disciplina antiga, originária da Índia, que objetiva o desenvolvimento integral da personalidade humana nos planos físico, mental e emocional. Ela é 
Yoga nas escolas: percepção de crianças e seus responsáveis sobre seus efeitos

Érica Maria Corrêa • Paula Hentschel Lobo da Costa

composta por oito aspectos/ramos: Yama (restrições comportamentais); Nyama (disciplinas diárias); Asana (posturas físicas); Pranayama (exercícios respiratórios); Pratyahar (controle dos sentidos); Dharana (concentração); Dhyana (meditação profunda); Samadhi (iluminação/elevação do ser).

Nas últimas décadas, os resultados favoráveis da prática do Yoga, realizada nas escolas por crianças, têm sido utilizados para recomendá-la como uma ferramenta complementar ao desenvolvimento integral dos escolares (EHUD et al., 2003; TELLES et al., 2013; FOLLETO et al., 2016).

A prática do Yoga também tem trazido benefícios acadêmicos e comportamentais para populações clínicas infantis como tratamento complementar para o Déficit de Atenção e Hiperatividade (MEHTA et al., 2011). Uma meta-análise na área da Psiquiatria demonstrou que a prevalência do Transtorno de Déficit de Atenção e Hiperatividade (TDAH) em crianças e jovens de até 18 anos é de 5,29\%, sendo que a variabilidade nesta estimativa ao redor do mundo deve-se, principalmente, às variações metodológicas dos estudos revisados e não pela localização geográfica em que essas crianças e jovens estavam inseridos (POLANCZYK et al., 2007).

Assim, considerando o debate dentro das comunidades pedagógica e médica sobre a prevalência de transtornos comportamentais e de aprendizagem, e seus efeitos sobre o desenvolvimento infantil, a prática do Yoga pode ser inserida no contexto escolar como alternativa complementar à formação dos alunos, mas não como um substituto à Educação Física Escolar, dados os objetivos insubstituíveis desta disciplina na formação das crianças, tais como explicitados na Base Nacional Comum Curricular (BRASIL, 2018).

A maioria dos estudos que discutem a prática do Yoga nas escolas foram conduzidos em países onde o Yoga é parte integrante da cultura local ou em países desenvolvidos. Desta maneira, seria importante obter subsídios a partir da realidade das escolas públicas brasileiras para uma discussão mais embasada acerca da viabilidade da inserção dessa prática como complemento ao cur- 
Yoga nas escolas: percepção de crianças e seus responsáveis sobre seus efeitos

Érica Maria Corrêa • Paula Hentschel Lobo da Costa

rículo escolar. Uma das etapas desta empreitada seria avaliar a percepção das crianças e de seus responsáveis sobre os efeitos da prática do Yoga no comportamento infantil, assim como se as crianças apreciariam ter essa nova prática inserida no seu contexto escolar.

Assim, a fim de que a prática do Yoga possa ser recomendada nas escolas públicas do Brasil como complemento à formação infantil integral, justifica-se a busca do conhecimento sobre a possibilidade de essa técnica ser de fato bem-sucedida sob as perspectivas dos pais/responsáveis e se conta com o interesse e o apreço das crianças.

Posto isso, o objetivo do presente estudo foi o de avaliar a percepção de um grupo de pais/responsáveis e seus filhos/as, frequentadores de uma escola pública localizada na periferia da cidade de São Paulo (BRASIL, 2018), a respeito dos efeitos da prática regular do Yoga realizada dentro da escola.

\section{Método}

O presente estudo recebeu aprovação do Comitê de Ética em Pesquisa com Seres Humanos da universidade e CONEP (Número do parecer: 2.708.965), assim como a aprovação do Conselho de Classe e da Diretoria da Escola onde a intervenção foi realizada. Pais/responsáveis e crianças assinaram o Termo de Consentimento Livre e Esclarecido e o Termo de Assentimento, respectivamente. Este estudo é parte integrante de um Ensaio Clínico Randomizado (ECR) que recebeu o registro de número RBR - 7rgyfvs no Registro Brasileiro de Ensaios Clínicos (REBEC), assim como no Universal Trial Number (UTN) de número UTN: U1111 - 1262 - 5016 e seguiu as recomendações do Consolidated Criteria for Reporting Qualitative Research (TONG et al., 2007).

Foram disponibilizadas 120 vagas, porém apenas 28 inscrições foram requeridas, sendo que duas crianças desistiram no início da intervenção, uma por falta de interesse na prática e outra por falta 
Yoga nas escolas: percepção de crianças e seus responsáveis sobre seus efeitos

de tempo, totalizando ao final 26 crianças. Elas foram distribuídas por sorteio em um grupo Yoga e um outro chamado de Lista de Espera. No segundo semestre de 2018, após sorteio dos inscritos, participaram do grupo Yoga 18 crianças. Oito crianças compuseram a Lista de Espera e realizaram as aulas de Yoga somente após o término do período de aulas do grupo Yoga. A amostra caracterizou-se por possuir crianças de ambos os sexos, com idades entre sete e 11 anos, estudantes do Ensino Fundamental I, integrantes de uma escola pública localizada em bairro da periferia da cidade de São Paulo (BRASIL, 2018). Não foram incluídas na análise de dados as respostas de crianças cujos pais/responsáveis ou a coordenação pedagógica tivessem informado a presença de transtornos prévios de qualquer ordem. Tal decisão metodológica deu-se ao fato de que esse aspecto poderia trazer covariáveis à análise que não seriam controladas. Contudo, todas as crianças interessadas foram encorajadas a participar das aulas de Yoga, contanto que tivessem a aprovação prévia de seus pais/responsáveis. A intervenção foi composta por 12 semanas de aulas de Yoga (posturas, exercícios respiratórios e meditação) de uma a duas vezes na semana, no contraturno escolar, das 12:00 às 13:00 horas, dentro da própria escola.

Após 12 semanas de intervenção, uma enquete desenvolvida pela própria pesquisadora foi entregue às crianças e outra aos seus respectivos responsáveis, contendo apenas uma questão aberta. As enquetes foram distribuídas na própria escola. Cada criança levou sua versão e a de seus pais/responsáveis para casa, a fim de que fossem preenchidas sem a presença do professor que conduziu as aulas de Yoga. Todas as respostas relativas às crianças que tiveram participação nas aulas de Yoga igual ou superior a 70\% foram levadas em consideração para a análise de dados.

Aos responsáveis foi questionado: "Descreva como foi para você e sua família a experiência do seu(sua) filho(a) ter participado das aulas de Yoga por 12 semanas". Já para as crianças: "Descreva como foi para você a experiência de ter participado das aulas de Yoga por 12 semanas". 
Yoga nas escolas: percepção de crianças e seus responsáveis sobre seus efeitos

Os resultados foram avaliados a partir de uma ferramenta qualitativa intitulada Discurso do Sujeito Coletivo - DSC (LEFÈVRE et al., 2003), cuja aplicabilidade é ampla no país, obedecendo-se criteriosamente a todas as etapas da técnica.

Seguindo esse método, a "pergunta ideal" deve obedecer aos seguintes critérios:

- Conduz o entrevistado a produzir um discurso;

- Traz a resposta exata referente ao assunto abordado;

- O entrevistado consegue responder o que ele realmente acha e não o que o entrevistador quer que ele responda;

- É acessível intelectualmente ao entrevistado;

- Passou por um projeto piloto antes de ser aplicada na intervenção.

A construção do DSC se dá através de coleta de depoimento (escrito, filmado ou gravado em áudio), na qual o conteúdo é dividido da seguinte maneira:

- Expressões-chave (ECH): são trechos do discurso que revelam a essência do relato e deve ser retratado da maneira literal como foi coletado, ou seja, com todos os vícios linguísticos, erros de concordância nominal/verbal apresentados pelo sujeito entrevistado;

- Ideia Central (IC): é a síntese da expressão-chave (ECH), que representa, da maneira mais fidedigna possível, o sentido de cada "ECH" coletado;

- Ancoragem (AC): nem sempre revelada nas expressões-chaves (ECH), a Ancoragem (AC) é a marca linguística do texto/fala do sujeito entrevistado, que reflete a crença que o mesmo tem sobre determinado assunto e que representa uma afirmação genérica que enquadra um determinado assunto. 
Yoga nas escolas: percepção de crianças e seus responsáveis sobre seus efeitos

Uma vez coletado e fragmentando cada discurso, o Discurso do Sujeito Coletivo (DSC) é construído como um discurso-síntese que, por sua vez, é composto pelas ECH que têm a mesma IC ou AC, onde a tabulação dos dados deve seguir rigorosamente as seguintes etapas:

- $1^{\text {a }}$ etapa: criar uma tabela intitulada Instrumento de Análise do Discurso (IAD 1) contendo três colunas (ECH, IC e AC) e copiar integralmente o conteúdo coletado de cada questão no ícone ECH (expressões-chave);

- $2^{\text {a }}$. etapa: identificar as ideias centrais (IC) e as ancoragens (AC), com recursos gráficos distintos;

- $3^{\text {a }}$. etapa: inserir as ideias centrais (IC) e as ancoragens (AC) em seu local específico na tabela;

- 4a . etapa: é iniciado o processo de etiquetamento das IC e $A C$ que tem o mesmo ou semelhante sentido (Etiqueta $A$, $B, C, D \ldots . .$.$) ;$

- $5^{\text {a }}$ etapa: criar um título para cada etiqueta que represente adequadamente cada uma delas;

- $6^{\text {a }}$. etapa: é criada uma outra tabela (IAD 2) contendo duas colunas (ECH ou IC e DSC), onde finalmente é construído o DSC (Discurso do Sujeito Coletivo). Esta etapa obedece a dois momentos, o primeiro é copiar/colar todos os $\mathrm{ECH}$ ou IC pertencentes a uma mesma etiqueta (Etiqueta A, B, C, D....) na coluna correspondente. O segundo momento é iniciar a escrita do DSC (Discurso do Sujeito Coletivo), sequenciando as ECH ou IC coletadas através das regras clássicas da língua portuguesa, com início, meio e fim, e com a presença de conectivos que deem sentido ao texto. O resultado pode ser apresentado de diversas maneiras e deve ser escrito na primeira pessoa, sendo que, não convém colocá-lo entre aspas, pois, não se trata de uma citação, e ainda segundo Lefèvre e Lefèvre (2003, p. 19): 
Yoga nas escolas: percepção de crianças e seus responsáveis sobre seus efeitos

[...] os discursos dos depoimentos não se anulam ou se reduzem a uma categoria comum unificadora já que o que se busca fazer é reconstruir, com pedaços de discursos individuais, como em um quebra-cabeça, tantos discursos-síntese quantos se julgue necessários para expressar uma dada "figura", ou seja, um dado pensar ou representação social sobre um fenômeno.

Já a intervenção baseou-se em metodologia desenvolvida por Khalsa (2016), descrita abaixo, que, por sua vez, baseou-se nos ensinamentos do psicólogo indiano e Mestre de Kundalini Yoga, Bhajan (2010). As aulas foram conduzidas por um profissional capacitado para lecionar Yoga, com experiência prévia com Yoga infantil, sendo dividida nas seguintes etapas:

1. Iniciação: as crianças se organizam em fila na entrada da sala de aula de Yoga e são convidadas a se concentrarem em tudo o que as estão deixando tristes, com raiva ou preocupadas. Ao passarem pelo "portal mágico", criado pela professora através de bambolê ou bolas de sabão, é dito que esses sentimentos vão embora, ficando apenas alegria e gentileza no coração. Enquanto as crianças passam por esse "portal mágico", a professora entoa (canta) um mantra (canto indiano);

2. Canto inicial: posicionadas em colchonetes dispostos em círculo, uma vela é acesa e colocada no centro desse círculo, com o objetivo de trazer para o concreto o conceito abstrato de expansão da "luz interior". Em seguida, é dito para as crianças: "para mantermos essa luz sempre brilhante, é necessário fazermos o bem para si e para os outros". Logo após, um mantra é iniciado e as crianças são convidadas a acompanharem. Ao final do mantra, a vela é retirada do círculo e colocada em local seguro;

3. Aquecimento: momento em que as crianças compartilham suas experiências, vivenciadas durante a semana, umas com as outras enquanto realizam trabalhos manuais, seja 
Yoga nas escolas: percepção de crianças e seus responsáveis sobre seus efeitos

através de pintura em papel, escultura com massa de modelar ou realizam posturas de Yoga (asanas) com o objetivo de se prepararem para a aula propriamente dita;

4. Kriya (aula): é o momento em que as posturas e exercícios respiratórios são introduzidos à aula. Isso é feito de maneira lúdica, através de brincadeiras, como pega-pega, esconde-esconde, estátua, pular corda, o mestre mandou, entre outras brincadeiras infantis de domínio público;

5. Relaxamento: momento em que as crianças descansam deitadas sobre seus colchonetes dispostos em círculo. Um outro mantra é iniciado através de aplicativo de música;

6. Meditação: igualmente vivenciada de maneira lúdica, o formato para a aula de Yoga Infantil, de acordo com os ensinamentos do Kundalini Yoga, intitula-se "Comunicação Celestial". Nele um mantra é entoado e, simultaneamente, realizam-se gestos com os dedos (mudras) e braços que, por sua vez, sincronizam-se com o significado da música;

7. Canto de encerramento: momento em que a vela é trazida novamente para o centro do círculo. Antes que seja apagada, é dito: "a vela será apagada, porém, nossa 'luz interior' nunca se apagará". Em seguida o mantra final é entoado e a aula encerrada.

\section{Resultados}

Os estudantes do grupo Yoga tiveram frequência às aulas acima de $70 \%$, enquanto os do grupo Lista de Espera tiveram participação abaixo de $50 \%$. Apenas os dados das enquetes de quem participou em $70 \%$ ou mais das aulas de Yoga foram levados em consideração para a análise de resultados. Sendo assim, foram analisadas 36 enquetes, sendo 18 das crianças e 18 dos seus respectivos responsáveis. Os discursos foram analisados e construídos separadamente (responsáveis e crianças). 
Yoga nas escolas: percepção de crianças e seus responsáveis sobre seus efeitos Érica Maria Corrêa • Paula Hentschel Lobo da Costa

Como pode ser verificado no discurso dos pais (Quadro 1), após as 12 semanas de intervenção, eles perceberam seus filhos/ as mais felizes, calmos, concentrados e relacionando-se melhor com seus familiares e colegas de escola. O relato de que o Yoga trouxe mais segurança e autoconfiança para a criança também foi trazido, porém, somente por uma mãe. Quase todos os pais/responsáveis relataram de que a experiência foi boa, mas curta, e que se a duração das aulas fosse maior, provavelmente os efeitos da intervenção teriam sido mais perceptíveis:

\begin{tabular}{|c|c|}
\hline ETIQUETA & Discurso do Sujeito Coletivo - DSC \\
\hline A - Felicidade & $\begin{array}{l}\text { "Meu filho/a chegava em casa feliz, gostava muito do Yoga, achei } \\
\text { ele/a muito entusiasmado, pude perceber o quanto ele/a ficava em- } \\
\text { polgado/a em participar das aulas e muitas vezes, repetia em casa o } \\
\text { que aprendia em aula. Fiquei satisfeito/a em perceber o interesse do } \\
\text { meu filho/a em participar das aulas, ele/a sentiu-se animado e isso } \\
\text { me deixou muito feliz." }\end{array}$ \\
\hline B - Calma e concentração & $\begin{array}{l}\text { "Meu filho/a aprendeu a escutar a sua respiração e a se acalmar } \\
\text { quando irritado/a. Na escola ele/a sempre foi agitado/a e com baixa } \\
\text { concentração, depois do Yoga ele/a melhorou, desenvolveu noções } \\
\text { de sequência, necessárias para tarefas do dia a dia, assim como, a } \\
\text { percepção para algumas coisas. Pude observar que ele/a parece estar } \\
\text { mais prestativo/a, além de ter aumentado relativamente o foco" }\end{array}$ \\
\hline $\begin{array}{l}\text { C - Qualidade nas interações } \\
\text { sociais }\end{array}$ & $\begin{array}{l}\text { "Após as aulas de Yoga, percebi que a qualidade das interações so- } \\
\text { ciais de meu filho/a melhorou, assim como, seu interesse em estar } \\
\text { em equipe, além de ter aprendido a respeitar mais os outros. Enfim, } \\
\text { parece ter ficado menos tenso e de ter controlado um pouco a ansie- } \\
\text { dade." }\end{array}$ \\
\hline $\begin{array}{l}\text { D - Experiência boa, mas } \\
\text { curta }\end{array}$ & $\begin{array}{l}\text { "Achei maravilhoso, se fosse uma experiência mais longa, creio que } \\
\text { o resultado teria sido melhor, gostaria que tivesse mais no próximo } \\
\text { ano. Poderia incluir no currículo escolar para crianças e jovens, pois, } \\
\text { devido ao pouco tempo de projeto, não notei mudanças significativas } \\
\text { no comportamento do meu filho/a, mas de uma maneira geral foi } \\
\text { bom." }\end{array}$ \\
\hline $\begin{array}{l}\text { E - Segurança e autoconfian- } \\
\text { ça }\end{array}$ & $\begin{array}{l}\text { "Percebi que ele/a sentiu-se mais seguro/a e autoconfiante após as } \\
\text { aulas de Yoga." }\end{array}$ \\
\hline
\end{tabular}

Fonte: As autoras (2021).

Já no discurso das crianças (Quadro 2), a prática do Yoga na escola foi percebida como uma experiência que trouxe divertimento, aprendizagem, calma, melhoras na qualidade das relações sociais 
Yoga nas escolas: percepção de crianças e seus responsáveis sobre seus efeitos Érica Maria Corrêa • Paula Hentschel Lobo da Costa

e, assim como os pais, as crianças observaram que apesar de ter sido uma experiência boa, ela foi curta:

\begin{tabular}{|l|l|}
\multicolumn{2}{l}{ Quadro 2 - Discurso do Sujeito Coletivo (DSC) - Crianças } \\
\hline ETIQUETA & Discurso do Sujeito Coletivo - DSC \\
\hline $\begin{array}{l}\text { A - Divertimento e aprendi- } \\
\text { zagem }\end{array}$ & $\begin{array}{l}\text { "Foi muito legal, aprendi várias brincadeiras, como respirar, concen- } \\
\text { trar, relaxar, além das posturas de Yoga. Ao mesmo tempo que foi } \\
\text { divertido, também foi um aprendizado e o que aprendi, ensinei para } \\
\text { meus familiares." }\end{array}$ \\
\hline B - Calma & $\begin{array}{l}\text { "Aprendi a meditar e a me acalmar quando agitado/a, parei de ser } \\
\text { agressivo/a e me senti mais tranquilo/a." }\end{array}$ \\
\hline $\begin{array}{l}\text { C - Qualidade nas interações } \\
\text { sociais }\end{array}$ & $\begin{array}{l}\text { "Foi muito bom, fiz novas amizades e brinquei com os amigos que } \\
\text { já tinha, me diverti muito. Aprendi a ajudar os outros e a falar as } \\
\text { "palavrinhas mágicas" (boa noite, bom dia, com licença, desculpe e } \\
\text { obrigado/a). As aulas de Yoga ajudaram a trazer amizade e união." }\end{array}$ \\
\hline $\begin{array}{l}\text { D - Experiência boa, mas } \\
\text { curta }\end{array}$ & $\begin{array}{l}\text { "As aulas de Yoga foram muito legais, pena que acabaram rápido, eu } \\
\text { não queria parar de fazer. Se continuar, gostaria de participar, pois, } \\
\text { gostei muito." }\end{array}$ \\
\hline
\end{tabular}

Fonte: As autoras (2021).

É interessante observar que para ambos, pais/responsáveis e crianças, os efeitos de 12 semanas de prática de Yoga foram semeIhantes, o que reforça os achados, porém, todos/as avaliaram que a duração foi curta.

\section{Discussão}

Objetivou-se com esse estudo identificar as percepções das crianças e de seus responsáveis sobre os efeitos da prática de Yoga realizada na escola sobre o comportamento infantil. Os depoimentos foram analisados através da metodologia do Discurso do Sujeito Coletivo (LEFÈVRE et al., 2003).

Os estudantes do grupo Yoga tiveram frequência às aulas acima de 70\%, enquanto os do grupo Lista de Espera tiveram participação abaixo de $50 \%$. Uma das possíveis razões para o baixo interesse das crianças do grupo Lista de Espera na participação nas aulas de Yoga pode dever-se ao fato de que a intervenção foi 
Yoga nas escolas: percepção de crianças e seus responsáveis sobre seus efeitos

oferecida a esse grupo entre os meses de novembro de 2018 e fevereiro de 2019, portanto durante as férias escolares (dezembro) e uma greve de professores (fevereiro). Esta situação pode ter prejudicado o interesse das crianças e seus responsáveis na intervenção oferecida.

Há evidências de que quando praticado por crianças e jovens como parte do currículo escolar o Yoga aumenta a capacidade de planejar e executar tarefas cognitivas (TELLES et al., 2013), melhorando a habilidade de planejamento e o comportamento autorregulatório (TSENG et al., 2000).

Os efeitos já conhecidos corroboram a compreensão do que foi observado pelos pais/responsáveis e pelas crianças do presente estudo: no período em que as crianças participaram nas aulas de Yoga, os responsáveis afirmaram perceber seus filhos/ as mais tranquilos, concentrados e as crianças relataram que as aulas de Yoga Ihes trouxeram calma e uma sensação de bem-estar. Resultados semelhantes também foram encontrados após 10 semanas de intervenção de Yoga com frequência de uma a duas vezes semanais em escolas norte-americanas (SARKISSIAN et al., 2018), assim como após 16 semanas de Yoga e Meditação de Atenção Plena realizadas também em escolas norte-americanas, com melhora nos índices de calma, regulação emocional e do controle do estresse (DARIOTIS et al., 2016).

Outro aspecto também percebido por pais e crianças deste estudo foi a melhora na qualidade das relações interpessoais durante o período de intervenção. Já foi demostrado que a prática do Yoga é capaz de reduzir de forma importante os índices de bullying em uma escola norte-americana de alto padrão socioeconômico (MARIE et al., 2006).

No presente estudo, uma das mães afirmou ter observado uma melhora na segurança e autoconfiança de seu filho durante a intervenção. Melhoras na autoestima de crianças que vivem em condições de alta vulnerabilidade social e na capacidade delas em usar estratégias para controlar o comportamento em situações es- 
Yoga nas escolas: percepção de crianças e seus responsáveis sobre seus efeitos

tressantes também foram observados com a prática do Yoga em uma escola norte-americana (SMITH et al., 2010) e outra na Índia (BHARDWAJ et al., 2013).

Por fim, as crianças e seus responsáveis relataram que apesar de terem apreciado a experiência das aulas de Yoga na escola, 12 semanas de prática não foram suficientes para que os efeitos do Yoga fossem mais permanentes. Esta fala coletiva permite compreender os resultados positivos de uma longa experiência de aulas de Yoga em uma escola norte-americana com intervenções diárias de cinco a 15 minutos, cinco vezes por semana, no decorrer de um ano letivo, que produziu melhora significativa em indicadores de bem-estar físico, mental e comportamental das crianças participantes (CHEN et al., 2014). Por outro lado, o presente estudo não pôde dar uma resposta à questão sobre a efetividade da duração da prática, pois não foram testadas diferentes durações da intervenção. Assim, se seria possível obter os mesmos resultados com intervenções mais curtas ou se haveria resultados ainda mais significativos com uma prática extensiva, inserida no currículo escolar, são questões que ainda precisam ser investigadas.

É possível também compreender os resultados aqui apresentados a partir dos efeitos de técnicas do Kundalini Yoga sobre o Sistema Nervoso Central. A Meditação aciona o córtex pré-frontal que é região responsável pela atenção, entre outros aspectos. Este, consequentemente, ativa o giro cingulado que é a área responsável pela resolução de conflitos, que, por sua vez, ativa o tálamo que promove a integração do sistema sensorial com o sistema nervoso central, região esta que é parte integrante do lobo límbico (comportamento emocional). Assim, através destas conexões, o praticante redimensiona as informações absorvidas do meio e, como consequência, a qualidade da resposta aos estímulos externos melhora, ocorrendo o que pode se chamar de controle dos sentidos (KHALSA, 2015).

Apesar do estudo ter apresentado resultados promissores, é preciso ponderar que o número de participantes dessa pesquisa foi pequeno (apenas 18 crianças do Grupo Yoga), prejudicando a 
Yoga nas escolas: percepção de crianças e seus responsáveis sobre seus efeitos

sua reprodutibilidade, assim como a generalização dos resultados. É importante também considerar que colocar a prática do Yoga no contraturno escolar não nos pareceu ser o mais recomendável, pois alguns pais/responsáveis alegaram que, apesar de interessados, os horários rígidos do serviço de transporte escolar público/ privado impediram a participação de seus filhos na intervenção. Outro aspecto de cunho prático foi a possibilidade de que o desconhecimento de alguns pais/responsáveis sobre o que seria a prática do Yoga levou muitos a não concordarem que seus filhos/as participassem da intervenção. Esse fato requer um trabalho prévio na escola com pais/responsáveis e professores/as acerca das características dessa prática, eliminando qualquer possibilidade de que seja atribuída à prática do Yoga uma conotação religiosa ou mística.

Para evitar tal rotulação, é importante ressaltar que a prática do Yoga também encontra respaldo na Base Nacional Comum Curricular do Ensino Fundamental (BRASIL, 2018), onde a Educação Física é o componente voltado à tematização das práticas corporais em suas diversas formas de codificação e significação social, devendo assegurar aos alunos/as os conhecimentos que thes permitam ampliar sua consciência a respeito de seus movimentos e dos recursos para o cuidado de si e dos outros. O Yoga está inserido nesse contexto, sendo parte integrante da subdivisão "Ginásticas de Conscientização Corporal", pertencente à área temática "Ginástica":

As ginásticas de conscientização corporal reúnem práticas que empregam movimentos suaves e lentos, tal como a recorrência a posturas ou à conscientização de exercícios respiratórios, voltados para a obtenção de uma melhor percepção sobre o próprio corpo. Algumas dessas práticas que constituem esse grupo têm origem em práticas corporais milenares da cultura oriental (BNCC, 2018, p. 218).

Para viabilizar o acesso a todo o conhecimento e, consequentemente, ao desenvolvimento integral oferecido pelo Yoga, o foco 
Yoga nas escolas: percepção de crianças e seus responsáveis sobre seus efeitos

durante a intervenção no presente estudo esteve sempre orientado para o que transcendia a realização em si de posturas, exercícios respiratórios e meditação. Questões relacionadas ao autoconhecimento das crianças, comportamentos éticos, alimentação saudável, respeito ao meio ambiente e, principalmente, ao fortalecimento do senso de coletividade, ou seja, a consciência de si e o respeito ao outro, foram enfatizados em todas as aulas. Pensando na função social da escola pública no Brasil e considerando-a um espaço de aprendizagens que transcendem os muros da escola e colaboram para a formação integral do indivíduo (Pacheco, 2014), a prática do Yoga pode compor esse escopo, contribuindo para a construção e o fortalecimento da cidadania de crianças e jovens.

Assim, considerando o amparo legal, os benefícios já conhecidos e o apreço das crianças e de seus responsáveis pela prática do Yoga no contexto escolar, conforme demonstrado aqui, é possível se pensar em estratégias para inserir alguns elementos do Yoga no cotidiano escolar, seja como um dos possíveis conteúdos abordados na Educação Física Escolar, seja como alternativa pedagógica complementar, em benefício da formação integral de crianças e jovens em sala de aula.

Por exemplo, após um período de treinamento com professor/a especializado/a em Yoga, professores/as de Educação Física, Pedagogos/as e seus auxiliares poderiam praticar com seus alunos/as algumas técnicas do Yoga, tais como: exercícios respiratórios e de concentração (meditação), em sessões de curta duração e com frequência diária, sem a necessidade de alterar a rotina escolar e sem a exigência de que um profissional especializado em Yoga seja o responsável por conduzir a prática. Tal treinamento poderia ocorrer, por exemplo, nos Diretórios Regionais de Educação (DRE's), após a devida aprovação das Secretarias de Educação, onde o/a professor/a de Yoga poderia ministrar essa capacitação dos/as pedagogos/as e professores/as de Educação Física, até mesmo de forma voluntária.

Em conclusão, um programa de 12 semanas de prática de Yoga trouxe calma, concentração e melhora nas relações interpessoais 
Yoga nas escolas: percepção de crianças e seus responsáveis sobre seus efeitos

das crianças, foi aprovado e apreciado pelo grupo de crianças que a praticaram na escola e seus responsáveis, indicando que o Yoga pode ser um instrumento complementar com potencial para contribuir para com a formação e a saúde integral das crianças.

\section{Referências Bibliográficas}

BENAVIDES, S. et al. Ashtanga Yoga for children and adolescents for weight management and psychological well-being: an uncontrolled open pilot study. Complementary Therapies in Clinical Practice, v. 15, n. 2, p. 110-114, 2009.

BIRDEE, G.S. et al. Clinical applications of Yoga for the pediatric population: a systematic review. Acad Pediatr, Brasil, v. 9, n. 4, p. 212-220, 2009.

BHAJAN, Yogi. The Aquarian Teacher: Treinamento Internacional de Professores de Kundalini Yoga como Ensinado por Yogi Bhajan. 5a ed. São Paulo: Editora Gobinde, 2010.

BHARDWAJ, A.K. et al. Yoga practice enhances the level of self-esteem in pre-adolescent school children. IJPSS, v. 3, n. 10, p. 189199, 2013.

BRASIL. Ministério da Educação e Cultura. Base Nacional Comum Curricular. Brasília, DF. 2018.

BRASIL. Ministério da Saúde. Portaria no 971, de 3 de maio de 2006. Aprova a Política Nacional de Práticas Integrativas e Complementares (PNPIC) no Sistema Único de Saúde. Brasília, DF. 2006.

BRASIL. Ministério da Saúde. Portaria no 849, de 27 de março de 2017. Inclui a Arteterapia, Ayurveda, Biodança, Dança Circular, Meditação, Musicoterapia, Naturopatia, Osteopatia, Quiropraxia, Reflexoterapia, Reiki, Shantala, Terapia Comunitária Integrativa e Yoga à Política Nacional de Práticas Integrativas e Complementares. Brasília, DF. 2017. 
Yoga nas escolas: percepção de crianças e seus responsáveis sobre seus efeitos

BRASIL. Secretaria Municipal de Assistência e Desenvolvimento Social. Índice de Vulnerabilidade Social. São Paulo, SP:

Secretaria Municipal de Assistência e Desenvolvimento Social. 2018. Disponível em: https://www.prefeitura.sp.gov.br/cidade/secretarias/upload/servicos/Mapa_IPVS_por_Prefeituras_Regionais. jpg. Acesso em: jan. 2019.

CHEN, D.D. et al. Perceived benefits on incorporating Yoga into classroom teaching: assessment of the effects of "Yoga Tools for Teacher". Advances in Physical Education, n. 4, p. 138-148, 2014.

DARIOTIS, J.K. et al. A qualitative evaluation of student learning and skills use in a school-based mindfulness and Yoga Program. Mindfulness (N Y), v. 7, n. 1, p. 76-89, 2016.

EHUD, M. et al. Here and Now: Yoga in Israeli Schools. Int J Yoga, v. 3, n. 2, p. 42-47, 2010.

FOLLETO, J.C. et. al. The Effects of Yoga Practice in School Physical Education on Children's Motor Abilities and Social Behavior. Int J Yoga, v. 9, n. 2, p. 156-162, 2016.

GALANTINO, M. et al. Therapeutic effects of yoga for children: A systematic review of literature. Pediatr Phys Ther, v. 20, n. 1, p. 66-80, 2008.

GHAROTE, ML. Yoga Aplicada: da teoria à prática. São Paulo: Phorte Editora, 2005.

HAGEN I. et al. Yoga for children and young people's mental health and well-being: Research review and reflections on the mental health potentials of yoga. Front Psychiatry, n. 5, p. 1-6, 2014.

HAGINS M. et al. A Randomized Controlled Trial on the Effects of Yoga on Stress Reactivity in 6th Grade Students. Evidence-Based Complement Altern Med, 2013; 2013:607134.

KHALSA D.M. Stress, Meditation, and Alzheimer's Disease Prevention: Where The Evidence Stands. Journal of Alzheimer's Disease, v. 48, p. 1-12, 2015. 
Yoga nas escolas: percepção de crianças e seus responsáveis sobre seus efeitos

KHALSA, P.K. Yoga con niños: Juego - Conciencia - Pureza, elevando la experiencia infantil. $1^{\text {a }}$. ed. Chile: Editora Cuarto Próprio, 2016.

KHALSA, S.B.S. et al. Evaluation of the mental health benefits of yoga in a secondary school: a preliminary randomized controlled trial. J Behav Health Serv Res, v. 39, n. 1, p. 80-90, 2012.

LEFÈVRE F.; LEFÈVRE A.M.C. O discurso do sujeito coletivo: Um novo enfoque em pesquisa qualitativa (Desdobramentos). Ed. rev. e ampl. Caxias do Sul: EDUCS, 2003.

MEHTA, S. et al. Multimodal Behavior Program for ADHD Incorporating Yoga and Implemented by High School Volunteers: A Pilot Study. ISRN Pediatr, 2011; 2011:780745.

MARIE, D. et al. Yoga prevents bullying in school. Calming Kids: creating a non-violent world. Disponível em: https://calmingkids.org/about-ck/evidence-based-research-results/. Acesso em: fev. 2020.

NOGGLE, J.J. et al. Benefits of Yoga for Psychosocial Well-Being in a US High School Curriculum: A Preliminary Randomized Controlled Trial. Journal of Developmental \& Behavioral Pediatrics, v. 33, n. 3, p. 193-201, 2012.

PACHECO J. Aprender em Comunidade. 1a. ed. São Paulo: Edições SM, 2014.

PEREIRA, A.P. et al. Avaliação de crianças pré-escolares: relação entre testes de funções executivas e indicadores de desatenção e hiperatividade. Rev Psicopedag, v. 29, n. 90, p. 279-289, 2012.

POLANCZYK, G. et al. The Worldwide Prevalance of ADHD: A Systematic Review and Metaregression Analysis. Am. J. Psychiatry, v. 164, n. 6, p. 942-948, 2007.

SANTOS, A.G. et al. Yoga, uma abordagem complementar para o desenvolvimento psicomotor da criança na escola. Coleção Pesq Educ Fís, Brasil, v. 12, n. 4, p. 135-144, 2013. 
Yoga nas escolas: percepção de crianças e seus responsáveis sobre seus efeitos

Érica Maria Corrêa • Paula Hentschel Lobo da Costa

SARKISSIAN M. et al. Effects of a Kundalini Yoga Program on Elementary and Middle School Students'Stress, Affect and Resilience. J Dev Behav Pediatr, v. 39, n. 3, p. 210-216, 2018. SAROKTE, A.S. et al. Effects of Medhya Rasayana and Yogic practices in improvement of short-term memory among school-going children. AYU, v. 34, n. 4, p. 383-389, 2013.

SMITTH, J.C. et al. Perceptions of children who participated in a school-based yoga program. J Occup Ther Sch Early Interv, n. 3, p. 226-238, 2010.

TELLES, S. et al. Effect of yoga or physical exercise on physical, cognitive and emotional measures in children: a randomized controlled trial. Child Adolesc Psychiatry Ment Health, v. 7, n. 1, p. 37, 2013.

TONG, A. et al. Consolidated criteria for reporting qualitative research (COREQ): a 32-item checklist for interviews and focus groups. International Journal for Quality in Health Care, v. 19, n. 6, p. 349-357, 2007.

TSENG, M.H., et al. Perceptual-motor function of school-age children with slow handwriting speed. Am J OccupTher, v. 54, n. 1, p. 83-88, 2000.

\section{Publisher}

Universidade Federal de Goiás. Faculdade de Educação Física e Dança. Publicação no Portal de Periódicos UFG. As ideias expressadas neste artigo são de responsabilidade de seus autores, não representando, necessariamente, a opinião dos editores ou da universidade. 